\title{
One hundred years of science communication - from phrenology to the neurosciences
}

\author{
Daniel Martins de Barros
}

Barros DM. One hundred years of science communication - from phrenology to the neurosciences. Rev Med (São Paulo). 2016 JulyAug.;95(Special Issue 2):88-92.

ABSTRACT: The sciences of brain and behavior have long fascinated the lay public, eager to apply any novel knowledge to improve both individuals and society. Be it in the fields of education, public security, mind performance and so on, the advances of neuroscience have always being followed by the flourishing of the most varied promises using scientific

cience communication has been a challenge
since science was structured as its own area of knowledge. This is because the structuring process itself resulted in a distancing from society through development of the scientific method - often counterintuitive - and the creation of scientific jargon - making the language obscure and inaccessible to the layman ${ }^{1}$. The Scientific Revolution of the $16^{\text {th }}-18^{\text {th }}$ centuries involved a process of specialization of knowledge, in which fields of knowledge were becoming independent and reaching unprecedented advances - from the anatomical description of the human being to the establishment of the laws of gravity. The advancement of scientific methods - like the development arguments. This appropriation of knowledge, however, is seldom precise, dangerously leading people to misinformation and false beliefs. We argue that scientists ought to be proactive science communicators, reducing the risks of distortions and fulfilling their role in university extension.

KEYWORDS: Neurosciences; Brain. of optics, the growing sophistication of mathematics initiated a process in which scientists themselves became laymen outside their respective fields of knowledge $e^{2,3}$. Given this reality, with distance between citizens and scientists, communicating with the population has become both increasingly difficult and increasingly necessary. Communication is more difficult in the sense that there is a larger gap between the languages of both parties, and greater asymmetry of knowledge; at the same time it is ever more necessary because if scientists do not translate their knowledge, it becomes inaccessible for society.

In the $18^{\text {th }}$ century, as a reaction to such a gap, a movement emerged in Europe, notably in the UK and

Department of Psychiatry, University of São Paulo; Center for Interdisciplinary Research on Applied Neurosciences - NAPNA, São Paulo, Brazil.

Mailing address: Hospital das Clínicas da Faculdade de Medicina da USP, Instituto de Psiquiatria. Rua Dr. Ovídio Pires de Campos, 785, $1^{\circ}$ andar. Cerqueira César. 05403010 - São Paulo, SP, Brasil. e-mail: daniel.barros@usp.br 
Germany, called by some "romantic science", which sought to reunite the common man with scientific knowledge. The field is a contemporary of romanticism, and was influenced by this cultural movement, with scientists from different areas recapturing the value of the narrative, whether literary or pictorial, in structuring of knowledge, recognizing that the mechanization of nature is useful for description, but insufficient to promote its full understanding. Among such individuals are naturalists, with their explorations described in diaries and paintings, for example ${ }^{1}$. Communication took on a central role in this movement, since language would become the cornerstone of both the structuring of knowledge as well as its transmission. Discussing the use of jargon, Sword echoes this principle today, showing that while academics who are also writers do use jargon - a resource that is both useful to synthesize knowledge and effective in the art of dissuading readers - they do so carefully, in consideration of the reader ${ }^{4}$.

Criticized as unscientific and lacking rigor, romantic science did not prosper in academia, and was limited to a period of just over half a century between the $18^{\text {th }}$ and 19 th centuries. Faced with a logic increasingly present in peerpublished magazines and productivity criteria for securing research funding, communication waned over time, leading again to this fissure among fields of knowledge. In the midtwentieth century, the issue returned to the fore with the influential work by C.P. Snow ${ }^{5}$, The Two Cultures. Though not explicitly dealing with the matter of communication for the layman, he did however denounce the difficulties in communication that exist within the academic world itself, in which humanities and natural sciences began to despise each other to the detriment of both ${ }^{5}$.

Entering the second decade of the $21^{\text {st }}$ century, such a distance was still quite visible: although most scientists consider lay communication important, they have a schismatic view, considering scientific communication and public communication to be two different spheres ${ }^{2}$. This attitude creates two problems: science is transmitted only in part and is seen as something special. In the first case, instead of the process as a whole being communicated, only the scientific results are presented to the population, which hinders the understanding of the paths that led to such knowledge and a critical appraisal of the presented result. In addition, science maintains a privileged status, away from everyday life, contributing to its remoteness instead of bringing it closer to society - in fact, in a recent survey, about two-thirds of scientists in general, and neuroscientists in particular, felt that their area of expertise should not be part of general education ${ }^{2}$. Given this, and despite the fact that most scientists consider science communication to be part of their duties ${ }^{2}$ they have a schismatic approach to it that influences such activity: in their relationship with the press, for example, science professionals still want special treatment, to be seen as authorities and not subject to questioning ${ }^{3}$. Virtually all believe they should be able to review the information presented in the news text before publication, a practice with which virtually every journalist disagree ${ }^{6}$. Although they gladly welcome the media for its function as a means of spreading knowledge and the credibility it lends to research, the researchers are mistrustful of communicators' and journalists' appropriation and transformation of knowledge ${ }^{2}$.

While this distance is harmful for science as a whole, the lack of proper communication in the sciences related to the mind and brain may be especially important, in that such knowledge can and is used by society in any given way to pursue its goals - from psychoanalysis to the neurosciences, trying to understand, explain, predict and manipulate behavior, with different social actors appropriating knowledge to justify their interests ${ }^{7,89,10,11}$.

Even before the development of psychoanalysis, the brain emerged as a candidate responsible for behaviors ranging from crime to genius, and attempts to act on it were aimed at projects ranging from social control to education reform $9: 19^{\text {th }}$ century phrenology, which attributed specific functions to clearly defined brain regions, led to a wave of publications proposing practices with alleged scientific basis, ranging from social reforms to projects that today we might call self-help 9 . After Paul Broca located the speech area in the brain's left hemisphere, several theories began to emerge, attributing all kinds of maladies to the inharmonious functioning of the two halves of the brain; with exercise and healthy activities as recommended by phrenology doctors, however, it would be possible to prevent and combat problems such as crime, juvenile delinquency, madness and even improve the educational system ${ }^{9}$. What sounds innocent today, however, can be considered as one of the seeds of eugenics ${ }^{12}$. It should 
be pointed out that the spread of these ideas to society many times was not through irresponsible or distorted appropriation of medical knowledge, but through the action of the professionals themselves, transmitting knowledge with the aim of meeting certain social expectations. It can be inferred with some confidence that just transmitting information, taken as certain, without concomitant exposure to the scientific method - and above all without exposure to the uncertainties inherent in it - contributed to the fact that society took as truth what was conveniently transmitted to it as such - an example, among others, of how this selective presentation of science can make a major difference in the practical lives of the population ${ }^{3}$.

With the development of psychoanalysis and its subsequent success, the same movement can be identified. In Brazil, for example, even before the practice was formally recognized by International Psychoanalytic Association, between 1930s and 1940s, its principles were already circulating both in academia and the cultural scene of major cities like São Paulo and Rio de Janeiro, appearing in women's magazines, literary supplements, and then-thriving radio programs $s^{8}$. An interesting parallel can be drawn here with the trajectory of the institutionalization of science in the country a hundred years before, when prior to official practices or scientific schools, scientific thought had already spread among the literate class through cultural productions such as literary journals and artistic works ${ }^{1}$. According Fetz and Ferreira ${ }^{1}$, the possibility of communicating thought based on "connection between scientific reason, lyrical reason and aesthetic reason" influenced Brazilian science and was instrumental in the establishment of the national scientific body.

In terms of psychoanalysis specifically, the Brazilian Association of Psychoanalysis in São Paulo, even before receiving international validation, promoted scientific meetings that became social events, attended not only by doctors, but by members of the São Paulo elite. This demand of the general public was soon met by a proto-selfhelp literature with a psychoanalytic base ${ }^{8}$. And just like the previous phase of searching for a societal application for brain science, in Brazil there was an undeniable link between the pioneers of psychoanalysis and social, educational and hygiene projects, especially among members of the Brazilian League of Mental Hygiene, historically an advocate of eugenic principles as well ${ }^{8,12}$. The cultural penetration of psychoanalysis was so strong, that just as in the United States from the mid-twentieth century, psychiatric and psychoanalytic training were often confused. This can be noted, for example, in films, which by the end of that century chose to show an analyst's couch to portray a psychiatrist, regardless of context. Literature both fiction and nonfiction - was witness to these changes, following the rise and fall of psychoanalytic and humanistic discourse and its replacement by an attempt to move in the direction of the natural sciences ${ }^{10}$.

With the scientific discrediting of psychoanalysis in the late twentieth century (and its less impressive costeffectiveness when compared to the antidepressants boom) and with the humanities' discourse in attempting to explain society exhausted, the market for scientific books exploded. Non-fiction works have proliferated, seeking to satisfy people's desire for explanations for all that the humanities could not ${ }^{3}$, while fiction novels have entered a phase in which knowledge newly acquired through neuroscience began to substitute for Freudian theories, with neurons, synapses and CT scans replacing Oedipal conflicts ${ }^{10}$. Even Woody Allen, perhaps the most Freudian filmmaker of all time, so tied to the psychoanalytic model in works such as All You Ever Wanted to Know about Sex (1972) or Zelig (1983), moves away from it, invoking illnesses such as a brain tumor and dementia to explain the behavior of characters in the film Everyone Says I Love You, 1996, or OCD in Whatever Works, from $2009^{13}$. Beginning in the 2000s, drugs begun to replace the analyst's couch in Hollywood as well.

But the neurosciences fare no better than phrenology or psychoanalysis in terms of transfer of knowledge to society. With the advent of the "Decade of the Brain," the U.S. government initiative to "enhance public awareness of the benefits to be gained by brain research," in the words of a declaration that decreed that "the decade that begins on January 1, 1990 is designated as the "Decade of the Brain"14, neuroscientific knowledge actually expanded at a very fast pace. Again, however, this knowledge was not properly offered to society. In a study of 2,931 UK newspapers reports published between 2000 and 2010, the same tendency toward self-help found in previous scientific periods still remains: the brain is seen as capital 
to be developed to increase power and secure advantages. And once again, scientific advances are used as a way to try to give materiality to human subjectivity, naturalizing phenomena as diverse as prejudice or malice by presenting a supposed biological basis for their occurrence. Worse, researchers found that, if misused, findings could be used as a means for segregation, justifying discrimination of various kinds ${ }^{11,15,16}$. In fact, adding the prefix "neuro" seems to increase the rhetorical force of several arguments, where one sees the recent proliferation of such areas as neuroeconomy, neuromarketing, neuroeducation and so on ${ }^{11}$.

One problem is the already mentioned incomplete, partial communication: in assessing how news on neuroimaging in particular is communicated, the field is dominated by biases such as presentation of only results, and ignoring of methods, resulting in uncritical coverage in the press; even issues like validity and effect size, important given the advancement of these techniques, seem not to be concerns of the media ${ }^{15}$. On the other hand, the ethical debate, in turn, finds more ground in the lay press than in the specialized press, as scientists are not concerned with such issues, leaving it to the care of society ${ }^{15}$. And what's even more worrisome: the reading of popular science magazines or newspapers offers very little or no effect on the knowledge of the general public regarding the brain, according to research conducted in Brazil ${ }^{7}$.

The problem is that neuroscientific knowledge, will, one way or another, be absorbed by society. The desire to explain human behavior is eternal, and each supposed advance in this direction will result in extrapolation from academia to satisfy that curiosity. The act of receiving

\section{REFERENCES}

1. Fetz M, Ferreira LC. Demarcações em crise: a Segunda Revolução Científica e a crítica à formação do espírito científico moderno. In: XVI Congresso Brasileiro de Sociologia, 2013, Salvador. Anais. Salvador; 2013. Disponível em: https://www. researchgate.net/publication/249993252_Demarcacoes_em_ crise_a_Segunda_Revolucao_Cientifica_e_a_critica_a formacao_do_espirito_cientifico_moderno.

2. Peters HP. Gap between science and media revisited: scientists as public communicators. Proc Natl Acad Sci USA. 2013;110(Suppl 3):14102-9. doi: 10.1073/pnas.1212745110.

3. Rose SP. How to (or not to) communicate science. Biochem knowledge, however, is not passive - rather, it is done actively by members of an audience with their respective preconceptions; new knowledge is absorbed selectively, often only reinforcing opinions and previous actions where the idea would be to challenge them ${ }^{11}$.

It is the duty of academia to realize this, and place the need to improve communication with the public on its agenda. In reducing the distinction between scientific communication and lay communication, for example, the aura of mystery surrounding the knowledge can be removed, helping us to disclose not only results, but the method as a whole, including the role of doubt and transience of the responses. More than that, we must understand that human beings are at the receiving end of our messages, and only will appropriate knowledge by harmonizing this with real life. If we do not make that bridge, someone else will - whether they be journalists, or the readers themselves - in an attempt to frame the new in a familiar way, in order to incorporate $\mathrm{it}^{11}$. The discourse of romantic science can be instrumental in this process, assisting the public in understanding the relevance of neuroscience in their practical life. According to the acclaimed popularizer of science, Oliver Sacks ${ }^{17}$, the romantic science revived by Soviet psychologist Alexander Romanovich Luria in the $20^{\text {th }}$ century was in opposition to the reductionism of biological sciences, especially when it comes to the sciences of the brain and mind ${ }^{17}$. And today, when perhaps more than ever neurosciences advance and flood the media with news, keeping people thirsty for this knowledge, this effort should be an integral part of the work of scientists.

Soc Trans. 2003;31(2):307-12. doi: 10.1042/bst0310307.

4. Sword H. J de jargão. Serrote. 2013;14.

5. Snow CP. As duas culturas e uma segunda leitura: uma versão ampliada das duas culturas e a revolução científica. São Paulo: Edusp; 1995. p.33-4.

6. Peters HP. The interaction of journalists and scientific experts: co-operation and conflict between two professional cultures. Media Cult Soc. 1995;17(1):31-48. doi: $10.1177 / 016344395017001003$.

7. Herculano-Houzel S. Do you know your brain? A survey 
on public neuroscience literacy at the closing of the decade of the brain. Neuroscientist. 2002;8(2):98-110. doi: $10.1177 / 107385840200800206$.

8. Russo JA. Psychoanalysis in Brazil - Institutionalization and Dissemination among the Lay Public. EIAL Estud Interdisciplinarios Am Latina Caribe. 2007(18)1:63-80. Available from: file:///C:/Users/Administrador/Downloads/ Dialnet-PsychoanalysisInBrazil-4004766.pdf.

9. Ortega F. Elementos para uma história da neuroascese. Hist Cien Saude Manguinhos (Rio de Janeiro). 2009;16(3):621-40. http://dx.doi.org/10.1590/S0104-59702009000300003.

10. Roth M. Rise of the neuronovel. N+1 Magazine. 2009;(8):13951. Available from: https://nplusonemag.com/issue-8/essays/ the-rise-of-the-neuronovel/.

11. O'Connor C, Joffe H. How has neuroscience affected lay understandings of personhood? A review of the evidence. Public Underst Sci. 2013;22(3):254-68. doi: 10.1177/0963662513476812.

12. Costa JF. História da psiquiatria no Brasil. Rio de Janeiro: Garamond; 2007.
13. Landeira-Fernandez J, Cheniaux E. Cinema e loucura: conhecendo os transtornos mentais através dos filmes. Porto Alegre: Artmed; 2010.

14. Bush G. Presidential Proclamation 6158. Project on the Decade of the brain. Washington (DC); July 1990 [cited 2015 Oct 15]. Available from: http://www.loc.gov/loc/brain/ proclaim.html.

15. Racine E, Bar-Ilan O, Illes J. Brain imaging: a decade of coverage in the print media. Sci Commun. 2006;28(1):12242. doi: 10.1177/1075547006291990.

16. O'Connor C, Rees G, Joffe H. (2012). Neuroscience in the public sphere. Neuron. 2012;74(2):220-6. doi: 10.1016/j. neuron.2012.04.004.

17. Sacks O. Luria and "romantic science". In: Yasnitsky A, van der Veer R, Ferrari M. The Cambridge handbook of culturalhistorical psychology. Cambridge: Cambridge University Press; 2014. p.517-28. 